\title{
OPEN Effects of CYP2B6 polymorphisms on plasma nevirapine concentrations: a systematic review and meta-analysis
}

\author{
Ha Young Yoon ${ }^{1,4}$, Young Ah Cho ${ }^{2,3,4}$, Jeong Yee ${ }^{1 \bowtie}$ \& Hye Sun Gwak ${ }^{1 \bowtie}$
}

Cytochrome P450 (CYP) is involved in the metabolism of nevirapine (NVP); especially, CYP2B6 has been known to be one of the main enzymes involved in NVP metabolism. The objective of this study was to investigate the effects of CYP2B6 variants on plasma concentrations of NVP by a systematic review and meta-analysis. A search for qualifying studies published until April 2020 was conducted using the EMBASE, PubMed, and Web of Science databases. The mean difference (MD) and 95\% confidence intervals (Cls) were calculated. Data analysis was performed using R Studio (version 3.6) and Review Manager (version 5.3). In total, data from six studies involving 634 patients were analyzed in the systematic review and five studies in the meta-analysis. We found that carriers of the CYP2B6 516 TT genotype had a $2.18 \mu \mathrm{g} / \mathrm{mL}$ higher NVP concentration than did the GG or GT $(95 \% \mathrm{Cl} 1.28-$ 3.08). In the respective comparisons of the three genotypes, it was found that the MD was $1.87 \mu \mathrm{g} /$ $\mathrm{mL}$ between the TT and GT groups, $2.53 \mu \mathrm{g} / \mathrm{mL}$ between TT and GG, and $0.60 \mu \mathrm{g} / \mathrm{mL}$ between GT and GG. This meta-analysis confirmed that CYP2B6 polymorphisms was associated with plasma NVP concentrations. Therefore, CYP2B6 genotyping may be useful to predict the responses to NVP.

Acquired Immunodeficiency Syndrome (AIDS) is one of the greatest public health challenges, with a World Health Organization (WHO) estimate of 37.9 million infected people around the world ${ }^{1}$. Ever since highly active antiretroviral therapy (HAART) was introduced in 1996, AIDS prognosis has greatly improved ${ }^{2}$. Typically, HAART targets multiple viral replication cycles and includes two nucleoside reverse transcriptase inhibitors (NRTIs), a non-nucleoside reverse transcriptase inhibitor (NNRTI), and a protease inhibitor (PI) or an integrase inhibitor (INSTI) ${ }^{3}$. Especially, NNRTIs decrease HIV-1 reverse transcriptase activity through allosteric inhibition.

Nevirapine (NVP), due to its low cost and high efficacy, is one of the most frequently utilized NNRTIs ${ }^{4,5}$. In NVP treatment, a significant relationship between trough concentrations and virologic response or toxicity has been reported ${ }^{6}$. Meanwhile, inter-individual variability in NVP plasma concentrations was observed to be approximately $50 \%$, where such variability could partially be explained by differences in ethnicity, gender, existence of hepatic disease and concomitant medications ${ }^{7-9}$. Additionally, genetic disposition was also shown to contribute to inter-individual variability in NVP concentrations ${ }^{10}$. Among the various genetic factors that may be associated with individual variability in NVP concentrations, genetic polymorphisms of the enzyme cytochrome $\mathrm{P} 450$ (CYP) are prime candidates, as NVP is principally metabolized by CYP3A4 and CYP2B6 into its major metabolites ${ }^{11,12}$

NVP undergoes significant oxidative metabolism to 2-, 3-, 8- and 12-hydroxynevirapine and 4-carboxynevirapine, followed by glucuronidation and renal excretion. A study reported that more than $80 \%$ of the radioactivity in urine was consisted of glucuronidated conjugates of hydroxylated NVP metabolites ${ }^{12}$. Among the metabolites, 2- and 3-hydroxynevirapine are known to be formed exclusively by CYP3A4 and CYP2B6, respectively. Since NVP has been suggested to be an inducer of the CYPs responsible for its own metabolism, and hepatic CYP2B genes are considered as the most-inducible CYP isoforms ${ }^{13}$, CYP2B6 could play an important role in NVP metabolism.

${ }^{1}$ College of Pharmacy and Graduate School of Pharmaceutical Sciences, Ewha Womans University, 52 Ewhayeodae-gil, Seodaemun-gu, Seoul 03760, Republic of Korea. ${ }^{2}$ College of Pharmacy, Gyeongsang National University, Jinju, Gyeongnam 52828, Republic of Korea. ${ }^{3}$ Mokhwa Convalescent Hospital, Jinju, Gyeongnam 52828, Republic of Korea. ${ }^{4}$ These authors contributed equally: Ha Young Yoon and Young Ah Cho. ${ }^{\bowtie}$ email: jjjhello1@ naver.com; hsgwak@ewha.ac.kr 


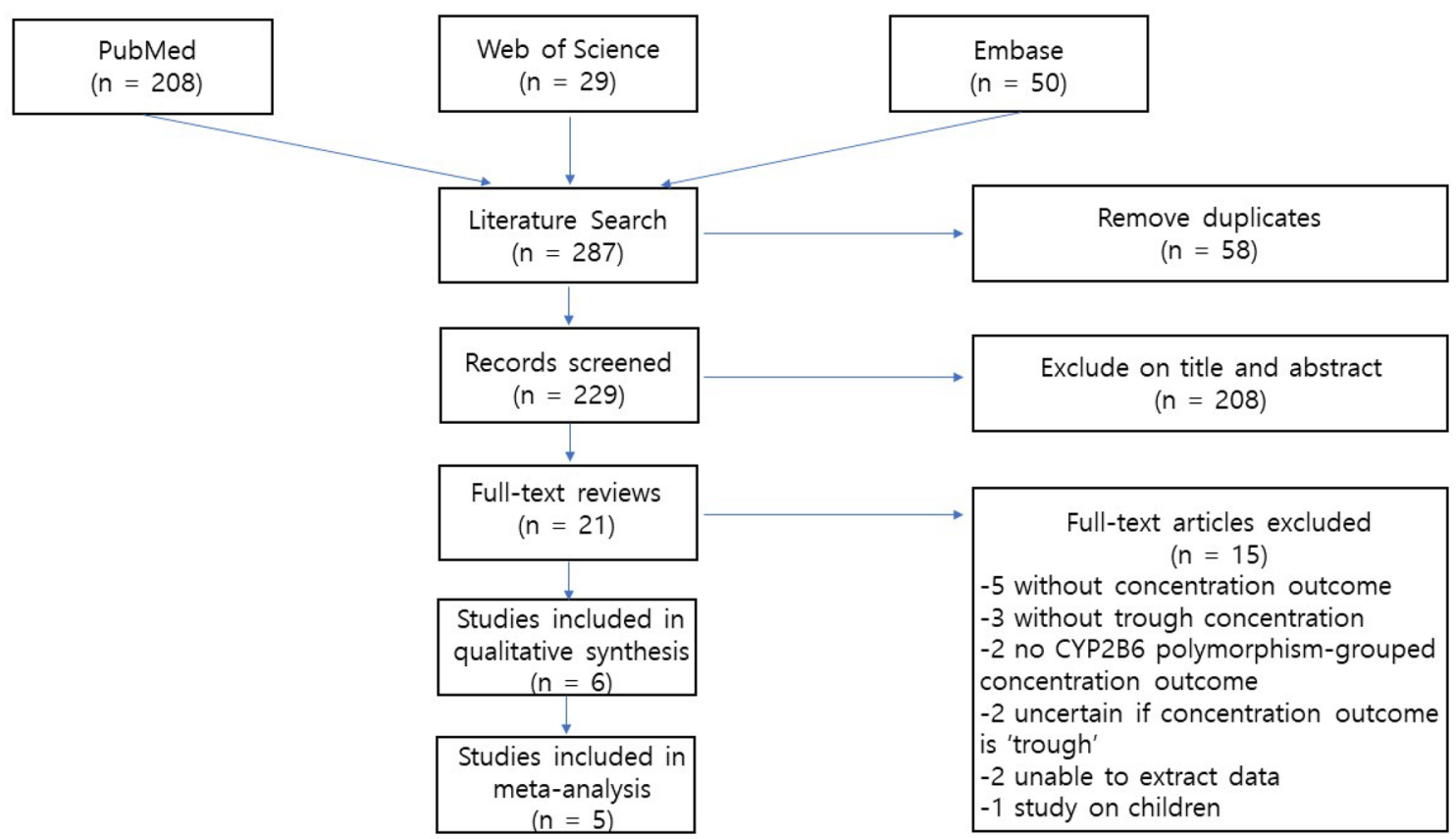

Figure 1. Flow diagram of included studies.

\begin{tabular}{|l|l|l|l|l|l|l|}
\hline First author & Study design & $\begin{array}{l}\text { Sample size (male } \\
\text { \%) }\end{array}$ & $\begin{array}{l}\text { Age (years) } \\
(\text { mean } \pm \text { SD) }\end{array}$ & Country & Alleles studied & Quality score \\
\hline Mahungu, 2009 & Cohort & $104(82.0)$ & $44.5 \pm 6.7$ & UK & $\begin{array}{l}516 \mathrm{G}>\mathrm{T}, 983 \mathrm{~T}>\mathrm{C}, \\
1459 \mathrm{C}>\mathrm{T}\end{array}$ & $7 / 11$ \\
\hline Uttayamakul, 2010 & RCT & $59(68.0)$ & $38.0 \pm 8.6$ & Thailand & $516 \mathrm{G}>\mathrm{T}$ & $6 / 13$ \\
\hline Gozalo, 2011 & RCT & $72(74.0)$ & $35.7 \pm 6.8$ & France & $\begin{array}{l}516 \mathrm{G}>\mathrm{T}, 785 \mathrm{~A}>\mathrm{G}, \\
1459 \mathrm{C}>\mathrm{T}\end{array}$ & $6 / 13$ \\
\hline Calcagno, 2012 & Cross-sectional & $204(29.9)$ & $39.3 \pm 11.2$ & Burundi & $516 \mathrm{G}>\mathrm{T}, 983 \mathrm{~T}>\mathrm{C}$ & $6 / 8$ \\
\hline Ramachandran, 2013 & RCT & $52(80.8)$ & $38.0 \pm 7.9$ & India & $516 \mathrm{G}>\mathrm{T}$ & $6 / 13$ \\
\hline Giacomelli, 2018 & Cohort & $143(61.5)$ & $47.7 \pm 7.7$ & Italy & $516 \mathrm{G}>\mathrm{T}$ & $9 / 11$ \\
\hline
\end{tabular}

Table 1. Characteristics of studies included in the systematic review. RCT randomized controlled trial.

Several studies have investigated the association between CYP2B6 gene polymorphisms and NVP concentration. However, since most such studies did not utilize a substantially large sample size, broad conclusions from separate studies are not readily attainable. Instead, assimilating data from such studies and deducing meaningful results from the pile of information is both prudent and necessary. In this context, we performed a meta-analysis of the published literature in search of significant conclusions on the effects of CYP2B6 genetic variants on plasma NVP concentrations.

\section{Results}

Literature search. A detailed flow chart of the study selection process is presented in Fig. 1. A total of 287 studies were identified from searches of three databases. After removal of 58 duplicates, 229 records were initially identified, of which the titles and abstracts were screened for inclusion in the study. From this initial review, 21 studies were selected for full-text reviews and assessed for eligibility. Of these studies, 15 were excluded for the following reasons; there were no concentration outcomes $(n=5)$, no trough concentration $(n=3)$, no CYP2B6 polymorphism-grouped concentration outcomes $(n=2)$, the researchers were not sure if the concentration outcomes were trough $(n=2)$, unable to extract the data $(n=2)$ and a study on children $(n=1)$. Although the study by Manhungu ${ }^{14}$ had one patient who received $600 \mathrm{mg}$ once daily, we included the study because most patients (99\%) underwent either $400 \mathrm{mg}$ once daily or $200 \mathrm{mg}$ twice daily. Ultimately, six articles were selected for this systematic review ${ }^{14-19}$.

The characteristics of the included studies are presented in Table 1. The studies were published from 2009 to 2018. Two of them were conducted in Asia, one in Africa, and three in Europe. There were three randomized controlled trials, two cohort studies, and one cross-sectional study, with Joanna Briggs Institutes (JBI) Critical Appraisal scores ${ }^{20}$ ranging from 6 to 9 . 
(A)

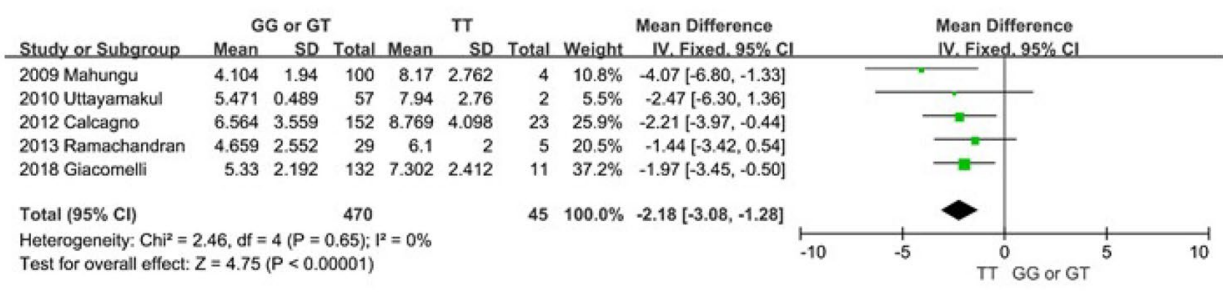

(B)

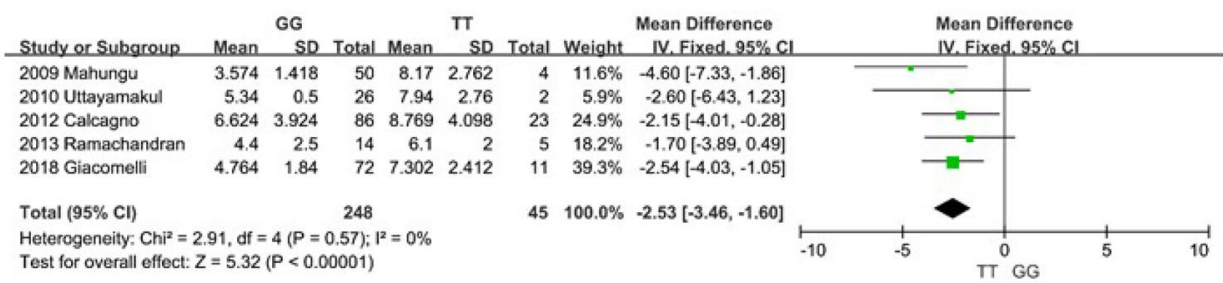

(C)

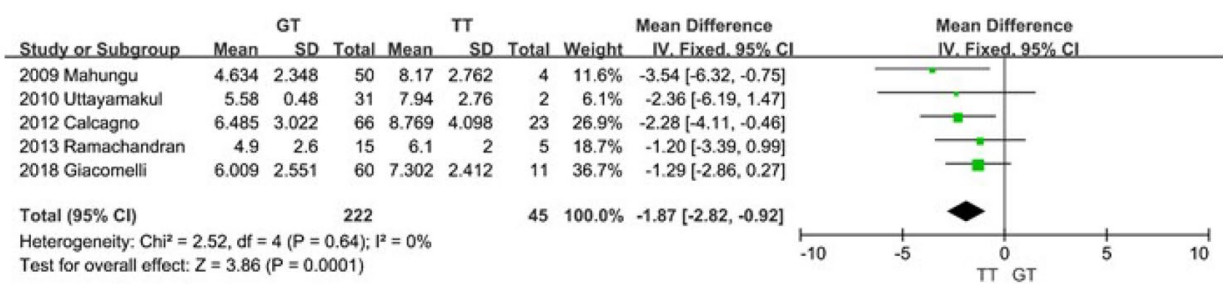

(D)

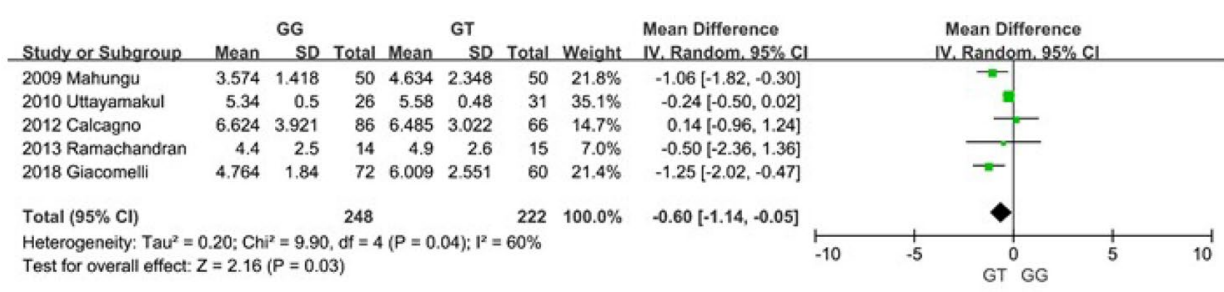

Figure 2. Forest plots demonstrating the association between CYP2B6 $516 \mathrm{G}>\mathrm{T}$ polymorphisms and plasma trough concentration $(\mu \mathrm{g} / \mathrm{mL})$ of nevirapine; (A) GG or GT versus TT; (B) GG versus TT; (C) GT versus TT; (D) GG versus GT.

CYP2B6 516 G >T. Six studies were evaluated to investigate the association between CYP2B6 polymorphisms and trough concentrations of NVP, which involved data from 634 patients. The most frequently studied polymorphism was $516 \mathrm{G}>\mathrm{T}$. As one study only compared NVP concentrations between patients with GG genotypes and $\mathrm{T}$ allele carriers (GT or TT) ${ }^{16}$, data from 562 patients from the other five studies was included in meta-analysis. NVP concentrations in the CYP2B6 516TT genotype was $2.18 \mu \mathrm{g} / \mathrm{mL}$ (95\% confidence interval (CI): 1.28-3.08) higher compared with the concentration in the GG or GT genotypes (5.38 versus $7.56 \mu \mathrm{g} /$ $\mathrm{mL}$; Fig. 2A). There was no heterogeneity observed among studies $\left(\mathrm{I}^{2}=0 \%\right)$. Neither Begg's test nor Egger's test showed significant publication bias (Begg's test: $P=1.000$; Egger's test: $P=0.580$ ).

In respective comparisons of the three genotypes, every association was found to be significant. The mean difference (MD) was $2.53 \mu \mathrm{g} / \mathrm{mL}$ between TT and GG (95\% CI 1.60-3.46; Fig. 2B), $1.87 \mu \mathrm{g} / \mathrm{mL}$ between the TT and GT genotypes (95\% CI 0.92-2.82; Fig. 2C), and $0.60 \mu \mathrm{g} / \mathrm{mL}$ between GT and GG (95\% CI 0.05-1.14; Fig. 2D).

Subgroup analysis by ethnicity was also performed (Fig. 3). The MD between the TT and GG or GT genotypes for Asians, Africans and Caucasians were 1.66 (95\% CI - 0.10-3.42), 2.21 (95\% CI 0.44-3.97), and 2.44 (95\% CI 1.15-3.74), respectively. The subgroup analysis results were similar to that from the entire meta-analysis, and there was no significant difference depending on subgroup $(P=0.78)$.

Other CYP2B6 polymorphisms. There were two studies that investigated the polymorphism CYP2B6 $983 \mathrm{~T}>\mathrm{C}$, two studies that investigated $1459 \mathrm{C}>\mathrm{T}$, and one study that investigated $785 \mathrm{~A}>\mathrm{G}$ (Table 2). For $983 \mathrm{~T}>\mathrm{C}$, a study by Calcangno et al. ${ }^{17}$ showed that patients with the TC genotype exhibited significantly higher NVP concentrations compared to the TT genotype. Another study showed similar trends ${ }^{14}$; however, statistical significance was not attained. In two studies investigating $1459 \mathrm{C}>\mathrm{T}^{14,16}$, wild allele homozygote (CC) carriers displayed higher NVP concentrations than variant allele carriers (CT or TT), although this was also not statistically significant. Regarding $785 \mathrm{~A}>\mathrm{G}$, there was only one study ${ }^{16}$ and there was no significant difference between wild allele homozygotes and variant allele carriers. 


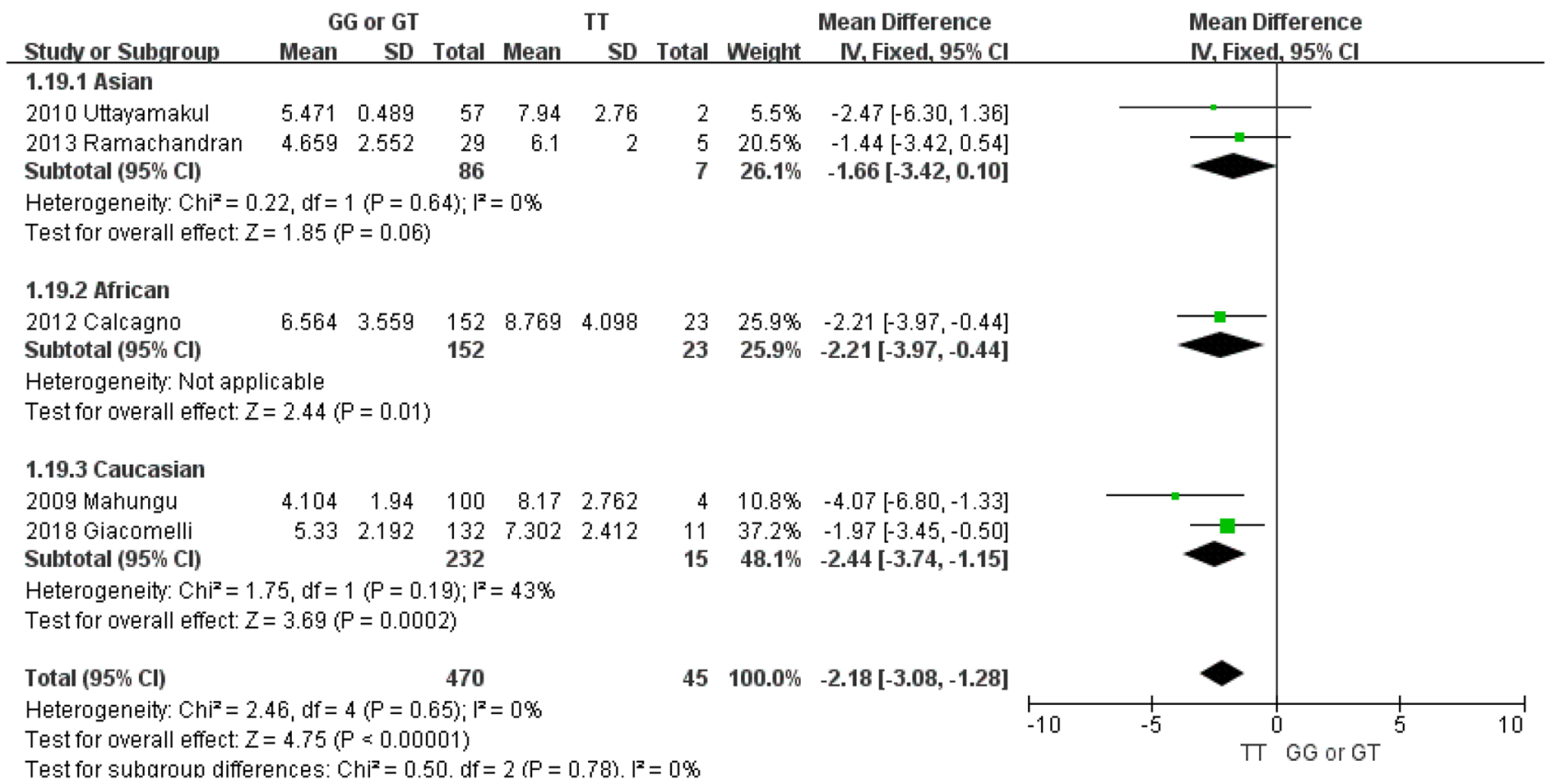

Figure 3. Forest plots of the subgroup analysis demonstrating the lack of association between the CYP2B6 516 $\mathrm{G}>\mathrm{T}$ polymorphism and plasma trough concentration $(\mu \mathrm{g} / \mathrm{mL})$ of nevirapine by ethnicity.

\begin{tabular}{|c|c|c|c|c|c|c|c|c|c|}
\hline \multirow[b]{2}{*}{ First author } & \multicolumn{3}{|l|}{$983 \mathrm{~T}>\mathrm{C}$} & \multicolumn{3}{|l|}{$1459 \mathrm{C}>\mathrm{T}$} & \multicolumn{3}{|l|}{$785 \mathrm{~A}>\mathrm{G}$} \\
\hline & TT & TC & $P$ & $\mathrm{CC}$ & CT or TT & $P$ & AA & AG or GG & $P$ \\
\hline $\begin{array}{l}\text { Mahungu, } \\
2009\end{array}$ & $\begin{array}{l}4.17 \pm 2.20 \\
(103)\end{array}$ & $5.806(1)$ & 0.52 & $\begin{array}{l}4.34 \pm 2.35 \\
(82)\end{array}$ & $\begin{array}{l}3.62 \pm 1.13 \\
(21)\end{array}$ & 0.15 & - & - & - \\
\hline Gozalo, 2011 & - & - & - & $\begin{array}{l}5.33 \pm 1.91 \\
(47)\end{array}$ & \begin{tabular}{|l}
$4.20 \pm 1.87$ \\
$(11)$
\end{tabular} & 0.14 & $\begin{array}{l}5.00 \pm 1.87 \\
(29)\end{array}$ & $\begin{array}{l}5.02 \pm 1.64 \\
(28)\end{array}$ & 0.85 \\
\hline Calcagno, 2012 & $\begin{array}{l}6.54 \pm 3.49 \\
(153)\end{array}$ & $\begin{array}{l}8.74 \pm 4.24 \\
(19)\end{array}$ & 0.012 & - & - & - & - & - & - \\
\hline
\end{tabular}

Table 2. Summaries of associations between CYP2B6 polymorphisms and nevirapine trough concentrations. Data were expressed as mean $\pm \mathrm{SD}$ (number of patients).

\section{Discussion}

This is the first meta-analysis evaluating the influence of CYP2B6 gene polymorphisms on NVP trough concentrations. HIV-infected patients with the CYP2B6 516TT genotype showed higher NVP concentrations than did GG or GT genotypes. Notable statistical significance was also attained in each of the three respective comparisons of genotypes. There was no difference between subgroups by ethnicity.

CYP2B6 is a member of the cytochrome P450 family, constituting approximately $2-10 \%$ of the total hepatic CYP content ${ }^{21}$ with significant inter-variability ${ }^{22}$. The difference in CYP2B6 mRNA and protein expression between individuals has been observed to be up to 250 -fold and 100 -fold, respectively ${ }^{22,23}$. Such variability is possibly due to effects of genetic polymorphisms, with one of the most frequently studied polymorphisms being $516 \mathrm{G}>\mathrm{T}$. CYP2B6 $516 \mathrm{G}>\mathrm{T}$, one of the two linked nonsynonymous polymorphisms in the ${ }^{\star} 6$ allele, is the causal mutation finally leading to reduced function. This results not only in an amino acid change but also in severely reduced levels of functional full-length mRNA transcript, protein, and activity ${ }^{24}$.

Several studies have investigated the association between $516 \mathrm{G}>\mathrm{T}$ and drug concentrations. According to these studies, $516 \mathrm{G}>\mathrm{T}$ polymorphism was associated with concentrations of drugs that are metabolized by CYP2B6 (e.g., methadone, propofol) ${ }^{25-27}$. In addition, as CYP2B6 is the major enzyme involved in the metabolism of efavirenz (EFV), another NNRTI, its polymorphism was shown to be related to EFV drug disposition. A recent meta-analysis noted that patients with the TT genotype exhibited significantly higher plasma concentrations of EFV compared with those that were homozygous for the G allele (MD: 2.98; 95\% CI 2.19-3.76) ${ }^{28}$. Thus, the results of this study that suggest an association between $516 \mathrm{G}>\mathrm{T}$ and NVP concentrations are in line with previous research.

There was no significant ethnicity-dependent difference in this study population. Patients with the TT genotype had higher NVP concentrations regardless of the ethnic background. This was consistent with the result from the aforementioned meta-analysis of $\mathrm{EFV}^{28}$, which reported that the higher EFV concentration in patients with the TT genotype was found within all ethnicity groups; overall EFV concentration in the TT genotype carriers was comparable between different ethnic groups. 
Higher plasma concentrations of NVP is one of the important issues regarding safety. In a clinical test conducted in China, hepatotoxicity was significantly associated with median NVP trough concentrations in male patients $(8.20$ vs. $5.48 \mu \mathrm{g} / \mathrm{mL}, P=0.015)$, along with hepatitis $C$ virus co-infection $(P=0.039)^{6}$. Gonzalez de Requena et al. also showed that among patients with chronic hepatitis $\mathrm{C}$ coinfection, NVP concentrations $>6 \mu \mathrm{g} /$ $\mathrm{mL}$ were associated with a $92 \%$ risk of liver toxicity ${ }^{29}$. A multivariate linear regression analysis also revealed that high trough concentrations was an independent predictor for elevated liver enzyme levels ${ }^{30}$. Moreover, several studies reported that the CYP2B6 $516 \mathrm{G}>\mathrm{T}$ polymorphism was associated with adverse events of NVP. According to Yuan et al. ${ }^{31}$, cutaneous adverse events were associated with CYP2B6 516 T (OR: 1.66; 95\% CI 1.29-2.15). Ciccacci et al. ${ }^{32}$ also suggested associations between CYP2B6 polymorphisms ( $516 \mathrm{G}>\mathrm{T}$ and $983 \mathrm{~T}>\mathrm{C}$ ) and SJS/ TEN susceptibility. Furthermore, another meta-analysis confirmed that patients with the GT and TT genotypes of $516 \mathrm{G}>\mathrm{T}$ displayed a significantly increased risk of EFV-induced side effects compared to those with the GG genotype, possibly due to the slow EFV clearance ${ }^{33}$.

In the selection process for AIDS treatment regimens, toxicity and long-term efficacy are factors of priority. Individual genetic variability may also be related to pharmacodynamics and pharmacokinetics of drugs, thus suggesting a need to develop therapy strategies tailor-made for different patients of varying genetic profiles. In developing countries, where HIV treatment options are limited, it may be especially beneficial to identify individual patient characteristics, including genetic polymorphisms. The data obtained in the present meta-analysis suggest that genotypes of CYP2B6 may be a useful factor in the identification of HIV-infected patients at risk of higher NVP concentrations.

This meta-analysis has some limitations that should be considered when interpreting the results. First, the limited number of studies may lead to low statistical power in detecting differences or heterogeneity. However, according to Herbison et al., meta-analyses with as few as four or five studies could produce robust results that are consistent with long-term results ${ }^{34}$. Second, some potential factors which could be associated with NVP (e.g., liver functions and concomitant drugs) could not be adjusted due to lack of information from individual studies. Third, the NVP dosing regimen was not identical; we included studies with patients that received either $400 \mathrm{mg}$ once daily or $200 \mathrm{mg}$ twice daily. Despite these shortcomings, this is the first systematic review and metaanalysis to evaluate the association between $C Y P 2 B 6$ polymorphisms and NVP concentrations. By combining the results of several studies, this current study suggests that CYP2B6 polymorphisms, especially $516 \mathrm{G}>\mathrm{T}$, may be associated with NVP trough concentrations in a significant way. Therefore, based on our findings, CYP2B6 genotyping may be useful in predicting response to NVP, although these results must be confirmed in studies on larger populations regarding pharmacodynamics.

\section{Methods and materials}

Literature search strategy and inclusion criteria. This meta-analysis was conducted according to the checklist outlined in the Preferred Reporting Items for Systematic Reviews and Meta-Analyses (PRISMA) ${ }^{35}$. Two reviewers independently searched published studies, which published until April 2020. An extensive search of electronic databases (PubMed, Web of Science, and EMBASE) was performed using the following search terms: (nevirapine OR NVP OR BI-RG-587 OR viramun*) AND (2B6 OR CYP2B6 OR Cytochrome P450 2B6 OR Cytochrome $\mathrm{p}-4502 \mathrm{~B} 6$ OR CYP2B6* OR P4502B6). There was no limitation on language.

Studies were included if (1) the studies evaluated the relationship of CYP2B6 genotypes with plasma trough concentrations of NVP $(\mu \mathrm{g} / \mathrm{mL}$ ) among HIV patients; (2) the patients received full-dose NVP (either $400 \mathrm{mg}$ once daily or $200 \mathrm{mg}$ twice daily) for at least 14 days or achieved steady-state conditions prior to pharmacokinetic sampling; and (3) the NVP concentration in plasma at $12 \mathrm{~h}$ after dosing ( $12 \pm 2 \mathrm{~h}$ ) were available and described separately according to different genotypes. Studies were excluded if they were (1) editorials, notes, abstracts, reviews, comments, letters, news, or editorials; (2) in vitro or in vivo studies; (3) unable to extract the data; (4) studies on children. In case of overlapping data, only the most recent and comprehensive data were included in the meta-analysis.

Data extraction and study quality assessment. Two reviewers independently extracted data, and discrepancies were resolved by consensus. Extracted data included the following information: name of first author, publication year, number of patients, mean age, percentage of males, ethnicity, studied alleles, and plasma trough concentrations of NVP.

Articles were assessed by two investigators based on the JBI Critical Appraisal Checklist for quality assessment. Quality was quantified by assigning scores ranging from 0 to 1 point/criteria. One point was assigned if the item was expressed in the study, and zero points were given if the item was not expressed or if it was unclear.

Statistical analysis. Meta-analysis was performed using Review Manager (version 5.3; The Cochrane Collaboration, Copenhagen, Denmark). The MD and 95\% CIs were used to identify the relationship between the existence of CYP2B6 polymorphisms and plasma trough concentrations of NVP. For studies that only reported medians and interquartile ranges, we retrieved mean and variance values from authors of original reports or used appropriate formulas to calculate mean and variance, making no assumption on the distribution of the underlying data ${ }^{36}$. The heterogeneity across studies was estimated by way of a chi-square test and an $\mathrm{I}^{2}$ statistic. An $\mathrm{I}^{2}$ value of $\geq 50 \%$ was considered to indicate significant heterogeneity. The choice of the proper effect model was based on the analysis results: the fixed effect model was used if $\mathrm{I}^{2}<50 \%$ and the random effect model was used if $\mathrm{I}^{2} \geq 50 \%{ }^{37}$. Subgroup analysis was performed according to ethnicity. Both Begg's rank correlation test and Egger's regression test of the funnel plot were also conducted using R Studio software (version 3.6.0; R Foundation for Statistical Computing, Vienna, Austria) to detect publication bias ${ }^{38,39}$. A $P$-value $<0.05$ was considered statistically significant. 
Received: 16 May 2020; Accepted: 21 September 2020

Published online: 15 October 2020

\section{References}

1. Joint United Nations Programme on HIV and AIDS (UNAIDS). Global HIV \& AIDS statistics 2019 fact sheet.https://www.unaid s.org/en/resources/fact-sheet.

2. Yuan, J. et al. Prevalence of liver injury among patients with acquired immunodeficiency syndrome treated with highly active antiretroviral therapy in China. J. Tradit. Chin. Med. 39, 275-280 (2019).

3. Wittkop, L. et al. Effect of transmitted drug resistance on virological and immunological response to initial combination antiretroviral therapy for HIV (EuroCoord-CHAIN joint project): a European multicohort study. Lancet Infect. Dis. 11, 363-371 (2011).

4. Ma, Q. et al. Pharmacokinetic drug interactions with non-nucleoside reverse transcriptase inhibitors. Expert Opin. Drug Metab. Toxicol. 1, 473-485 (2005).

5. Rotger, M. et al. Influence of CYP2B6 polymorphism on plasma and intracellular concentrations and toxicity of efavirenz and nevirapine in HIV-infected patients. Pharmacogenet. Genom. 15, 1-5 (2005).

6. Wang, J. et al. Nevirapine plasma concentrations are associated with virologic response and hepatotoxicity in Chinese patients with HIV infection. PLoS ONE 6, e26739 (2011).

7. Moltó, J. et al. Variability in non-nucleoside reverse transcriptase and protease inhibitors concentrations among HIV-infected adults in routine clinical practice. Br. J. Clin. Pharmacol. 63, 715-721 (2007).

8. Kappelhoff, B. S. et al. Nevirapine and efavirenz pharmacokinetics and covariate analysis in the $2 \mathrm{NN}$ study. Antivir. Ther. 10, 145-155 (2005).

9. Boehringer Ingelheim Pharmaceuticals, Inc. Viramune (nevirapine) prescribing information.https://www.accessdata.fda.gov/drugs atfda_docs/label/2011/020636s039_020933s030lbl.pdf.

10. Haas, D. W. Pharmacogenomics and HIV therapeutics. J. Infect. Dis. 191, 1397-1400 (2005).

11. Erickson, D. A., Mather, G., Trager, W. F., Levy, R. H. \& Keirns, J. J. Characterization of the in vitro biotransformation of the HIV-1 reverse transcriptase inhibitor nevirapine by human hepatic cytochromes P-450. Drug Metab. Dispos. 27, 1488-1495 (1999).

12. Riska, P. et al. Disposition and biotransformation of the antiretroviral drug nevirapine in humans. Drug Metab. Dispos. 27, 895-901 (1999).

13. Fan-Havard, P. et al. Pharmacokinetics of phase I nevirapine metabolites following a single dose and at steady state. Antimicrob. Agents Chemother. 57, 2154-2160 (2013).

14. Mahungu, T. W. et al. Cytochrome P450 2B6 516G->T is associated with plasma concentrations of nevirapine at both $200 \mathrm{mg}$ twice daily and $400 \mathrm{mg}$ once daily in an ethnically diverse population. HIV Med. 10, 310-317 (2009).

15. Uttayamakul, S. et al. Effects of CYP2B6 G516T polymorphisms on plasma efavirenz and nevirapine levels when co-administered with rifampicin in HIV/TB co-infected Thai adults. AIDS Res. Ther. 7, 8 (2010).

16. Gozalo, C. et al. Pharmacogenetics of toxicity, plasma trough concentration and treatment utcomeo with nevirapine-containing regimen in anti-retroviral-naïve HIV-infected adults: an Exploratory Study of the TRIANON ANRS 081 Trial. Basic Clin. Pharmacol. Toxicol. 109, 513-520 (2011).

17. Calcagno, A. et al. Influence of CYP2B6 and ABCB1 SNPs on nevirapine plasma concentrations in Burundese HIV-positive patients using dried sample spot devices. Br. J. Clin. Pharmacol. 74, 134-140 (2012).

18. Ramachandran, G. et al. Lack of association between plasma levels of non-nucleoside reverse transcriptase inhibitors \& virological outcomes during rifampicin co-administration in HIV-infected TB patients. Indian J. Med. Res. 138, 955-961 (2013).

19. Giacomelli, A. et al. Clinical and genetic determinants of nevirapine plasma trough concentration. SAGE Open Med. 6, 2050312118780861 (2018).

20. Wang, H. \& Tompkins, L. M. CYP2B6: new insights into a historically overlooked cytochrome P450 isozyme. Curr. Drug Metab. 9, 598-610 (2008).

21. Aromataris, E. \& Munn, Z. Joanna Briggs Institute reviewer's manual. The Joanna Briggs Institute. https://reviewersmanual.joann abriggs.org.

22. Code, E. L. et al. Human cytochrome P4502B6: interindividual hepatic expression, substrate specificity, and role in procarcinogen activation. Drug Metab. Dispos. 25, 985-993 (1997)

23. Zanger, U. M. et al. Polymorphic CYP2B6: molecular mechanisms and emerging clinical significance. Pharmacogenomics. 8, 743-759 (2007).

24. Hofmann, M. H. et al. Aberrant splicing caused by single nucleotide polymorphism c.516G>T [Q172H], a marker of CYP2B $6^{\star} 6$, is responsible for decreased expression and activity of CYP2B6 in liver. J. Pharmacol. Exp. Ther. 325, 284-292 (2008).

25. Thorn, C. F., Lamba, J. K., Lamba, V., Klein, T. E. \& Altman, R. B. PharmGKB summary: very important pharmacogene information for CYP2B6. Pharmacogenet. Genom. 20, 520-523 (2010).

26. Bart, G., Lenz, S., Straka, R. J. \& Brundage, R. C. Ethnic and genetic factors in methadone pharmacokinetics: a population pharmacokinetic study. Drug Alcohol Depend. 145, 185-193 (2014).

27. Mikstacki, A. et al. The effect of UGT1A9, CYP2B6 and CYP2C9 genes polymorphism on individual differences in propofol pharmacokinetics among Polish patients undergoing general anaesthesia. J. Appl. Genet. 58, 213-220 (2017).

28. Ayuso, P., Neary, M., Chiong, J. \& Owen, A. Meta-analysis of the effect of CYP2B6, CYP2A6, UGT2B7 and CAR polymorphisms on efavirenz plasma concentrations. J. Antimicrob. Chemother. 74, 3281-3290 (2019).

29. Gonzalez de Requena, D., Nunez, M., Jimenez-Nacher, I. \& Soriano, V. Liver toxicity caused by nevirapine. AIDS 16, 290-291 (2002).

30. De Requena, D. G., Jimenez-Nacher, I. \& Soriano, V. Changes in nevirapine plasma concentrations over time and its relationship with liver enzyme elevations. AIDS Res. Hum. Retroviruses 21, 555-559 (2005).

31. Yuan, J. et al. Toxicogenomics of nevirapine-associated cutaneous and hepatic adverse events among populations of African, Asian, and European descent. AIDS 25, 1271-1280 (2011).

32. Ciccacci, C. et al. Association between CYP2B6 polymorphisms and Nevirapine-induced SJS/TEN: a pharmacogenetics study. Eur. J. Clin. Pharmacol. 69, 1909-1916 (2013).

33. Cheng, L. et al. Meta-analysis of the associations of CYP2B6-516G $>$ T polymorphisms with efavirenz-induced central nervous system side effects and virological outcome in HIV-infected adults. Pharmacogenom. J. 20, 246-259 (2020).

34. Herbison, P., Hay-Smith, J. \& Gillespie, W. J. Meta-analyses of small numbers of trials often agree with longer-term results. J. Clin. Epidemiol. 64, 145-153 (2011).

35. Moher, D., Liberati, A., Tetzlaff, J., Altman, D. G., \& PRISMA Group. Preferred reporting items for systematic reviews and metaanalyses: the PRISMA statement. Ann. Intern. Med. 6, 264-269 (2009).

36. Wan, X., Wang, W., Liu, J. \& Tong, T. Estimating the sample mean and standard deviation from the sample size, median, range and/or interquartile range. BMC Med. Res. Methodol. 14, 135 (2014).

37. DerSimonian, R. \& Laird, N. Meta-analysis in clinical trials. Control Clin. Trials 7, 177-188 (1986)

38. Begg, C. B. \& Mazumdar, M. Operating characteristics of a rank correlation test for publication bias. Biometrics 50, 1088-1099 (1994). 
39. Egger, M., DaveySmith, G., Schneider, M. \& Minder, C. Bias in meta-analysis detected by a simple, graphical test. BMJ 315, 629-634 (1997).

\section{Acknowledgements}

None.

\section{Author contributions}

All the authors have made substantial contributions to the conception of the study. J.Y. and H.S.G. contributed to designing the study. H.Y.Y. and Y.A.C. contributed to acquisition and analysis of data. J.Y. and H.S.G. contributed to interpretation of data. H.Y.Y. and Y.A.C. contributed to drafting of the manuscript. J.Y. and H.S.G. contributed to critical revision of the manuscript. All authors approved the final manuscript.

\section{Funding}

We did not receive any funding.

\section{Competing interests}

The authors declare no competing interests.

\section{Additional information}

Correspondence and requests for materials should be addressed to J.Y. or H.S.G.

Reprints and permissions information is available at www.nature.com/reprints.

Publisher's note Springer Nature remains neutral with regard to jurisdictional claims in published maps and institutional affiliations.

(c) (i) Open Access This article is licensed under a Creative Commons Attribution 4.0 International License, which permits use, sharing, adaptation, distribution and reproduction in any medium or format, as long as you give appropriate credit to the original author(s) and the source, provide a link to the Creative Commons licence, and indicate if changes were made. The images or other third party material in this article are included in the article's Creative Commons licence, unless indicated otherwise in a credit line to the material. If material is not included in the article's Creative Commons licence and your intended use is not permitted by statutory regulation or exceeds the permitted use, you will need to obtain permission directly from the copyright holder. To view a copy of this licence, visit http://creativecommons.org/licenses/by/4.0/.

(C) The Author(s) 2020 